\title{
Induction of cortical granule exocytosis of pig oocytes by spermatozoa during meiotic maturation
}

\author{
W. H. Wang*, M. Hosoe and Y. Shioya \\ Department of Reproduction, National Institute of Animal Industry, Tsukuba Norindanchi, PO Box 5 , \\ Ibaraki 305, Japan
}

\begin{abstract}
Pig oocytes were examined to test their ability to undergo cortical granule exocytosis upon penetration by spermatozoa during meiotic maturation. Immature or maturing oocytes (cultured in vitro for $0 \mathrm{~h}, 26 \mathrm{~h}$ and $46 \mathrm{~h}$ ) were inseminated with ejaculated boar spermatozoa in vitro. Before and after insemination, oocytes were stained with peanut agglutinin labelled with fluorescein isothiocyanate and the cortical granule distributions were examined under the fluorescent microscope and the laser confocal microscope. Before insemination, all the oocytes at the germinal vesicle stage showed a uniform distribution of cortical granules throughout the cortical cytoplasm. The granules migrated centrifugally during maturation and were distributed just beneath the oolemma in the oocytes after germinal vesicle breakdown, forming a monolayer in metaphase I or metaphase II. Cortical granules were still present in all penetrated oocytes at the germinal vesicle stage $18 \mathrm{~h}$ after insemination; in contrast, $26 \%$ and $84 \%$ of the oocytes inseminated at the stages of germinal vesicle breakdown or at metaphase I and II, respectively, completely released their cortical granules. Nuclear activation rates of penetrated oocytes were $0 \%, 38 \%$ and $96 \%$ in oocytes cultured for $0 \mathrm{~h}, 26 \mathrm{~h}$ and $46 \mathrm{~h}$, respectively. Of the nuclear-activated oocytes, $67 \%$ (oocytes cultured for $26 \mathrm{~h}$ ) and $88 \%$ (oocytes cultured for $46 \mathrm{~h}$ ) released cortical granules completely. Complete cortical granule exocytosis was not observed in nuclear-inactivated oocytes. Of the nuclear-activated oocytes, $67 \%$ (oocytes cultured for $26 \mathrm{~h}$ ) and $80 \%$ (oocytes cultured for $46 \mathrm{~h}$ ) of monospermic oocytes and $67 \%$ (oocytes cultured for $26 \mathrm{~h}$ ) and $91 \%$ (oocytes cultured for $46 \mathrm{~h}$ ) of polyspermic oocytes released cortical granules, and no statistical difference was observed between oocytes cultured for $26 \mathrm{~h}$ or $46 \mathrm{~h}$, or between monospermic and polyspermic oocytes. The proportion of oocytes with cortical granule exocytosis increased as insemination time increased and was greatest $18 \mathrm{~h}$ after insemination in oocytes cultured for $26 \mathrm{~h}$ and $46 \mathrm{~h}$; no obvious changes were observed when the insemination time was prolonged to $24 \mathrm{~h}$. These results indicate that pig oocytes develop the ability to release cortical granules after penetration by spermatozoa following germinal vesicle breakdown, and that this ability is not fully developed until metaphase II. Cortical granule exocytosis is accompanied by nuclear activation, suggesting that both nuclear and cytoplasmic maturation are responsible for the cortical reaction. Polyspermy may be a result of a complete failure of cortical granule exocytosis in immature oocytes and delayed CG exocytosis in matured oocytes.
\end{abstract}

\section{Introduction}

In most mammalian species studied, fertilization takes place physiologically after ovulation. However, immature oocytes obtained from follicles can be penetrated by spermatozoa in vitro (mouse: Iwamatsu and Chang, 1972; hamster: Barros and Munoz, 1974; rabbit: Overstreet and Bedford, 1974; rat: Niwa and Chang, 1975; human: Overstreet et al., 1980;

*Present address and address for correspondence: 159 Animal Sciences Center, Department of Animal Science, University of Missouri-Columbia, Columbia, MO 65211, USA.

Received 19 August 1996
Trounson et al., 1982; Marrs et al., 1984; cattle: Niwa et al. 1991; pig: Wang et al., 1994). Penetration of immature pig oocytes by spermatozoa has also been observed in vivo after the induction of ovulation (Polge and Dzuik, 1965; Hunter et al. 1976). Higher proportions of penetrated immature oocytes were polyspermic compared with matured oocytes (Polge and Dzuik, 1965; Hunter et al., 1976; Trounson et al, 1982; Marrs et al., 1984; Niwa et al., 1991). The polyspermy in immature oocytes was attributed to the complete failure of cortical granule (CG) exocytosis (Moore and Bedford, 1978; Barrios and Bedford, 1979) because there is strong evidence that CG exocytosis plays a key role in blocking polyspermic 
penetration of the oolemma and/or in altering the properties of the zona pellucida of mammalian oocytes (Yanagimachi, 1994). The failure of CG exocytosis in immature oocytes has also been reported in sea urchins (Longo, 1978) and amphibians (Elinson, 1986). The ability of oocytes to release CGs is developed during meiotic maturation (Ducibella, 1991).

However, polyspermy in matured pig oocytes inseminated in vitro is very high (Niwa, 1993). Cran and Cheng (1986) and Yoshida et al. (1993) reported that pig oocytes matured both in vivo and in vitro can release CGs upon sperm penetration but some differences in these results were observed. The most distinct difference was that oocytes penetrated in vivo released CGs more quickly than oocytes penetrated in vitro and the contents of CGs dispersed in the perivitelline space (PVS) in vivo but not in vitro after exocytosis. The failure of the contents of CGs to disperse has also been observed in the human in vitro fertilization (IVF) system (Sathananthan and Trounson, 1982). According to a recent report by Dandekar and Talbot (1992), the formation of a new envelope by the CG exudate in the PVS may be important in blocking polyspermy in mammals, although only mouse, hamster and human oocytes were examined in the study.

Wang et al. (1994) reported that immature and maturing oocytes in pigs were penetrable by spermatozoa in vitro but that an equal degree of polyspermy was observed in immature and matured oocytes. Whether this is related to CG exocytosis is still unknown. For a better understanding of the mechanism of CG exocytosis in pig oocytes cultured and inseminated in vitro, it is necessary to determine the ability of oocytes at different stages to release CGs after sperm penetration. The present study was designed to determine this by examination of the competence of pig oocytes during meiotic maturation to release CGs after IVF. In addition, the relationships between CG exocytosis and sperm penetration, and between CG exocytosis and nuclear activation of oocytes, were examined.

\section{Materials and Methods}

\section{Medium}

The basic medium, designated TCM-199B, was tissue culture medium (TCM) 199 (with Earle's salts; Gibco, Grand Island, NY) supplemented with $2.92 \mathrm{mmol}$ calcium lactate $\mathrm{l}^{-1}$, $0.91 \mathrm{mmol}$ sodium pyruvate $1^{-1}, 3.05 \mathrm{mmol}$ D-glucose $1^{-1}$, $75 \mu \mathrm{g}$ potassium penicillin $\mathrm{G} \mathrm{ml}^{-1}, 50 \mu \mathrm{g}$ streptomycin sulfate $\mathrm{ml}^{-1}$ and $10 \%$ heat-inactivated fetal calf serum (FCS; Gibco). This medium was exactly the same as that used by Wang et al. (1995). For oocyte maturation, TCM-199B was supplemented with $0.57 \mathrm{mmol}$ cysteine $1^{-1}$ (Sigma Chemical Co., St Louis, $\mathrm{MO}$ ), 10 iu equine chorionic gonadotrophin $\mathrm{ml}^{-1}$ (Serotropin;

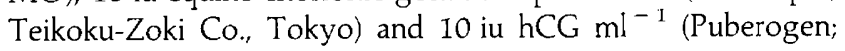
Sankyo Co., Tokyo).

\section{Collection and culture of oocytes}

Ovaries were collected from maturing gilts at a local abattoir and transported to the laboratory within $1-1.5 \mathrm{~h}$ of collection in $0.9 \%(\mathrm{w} / \mathrm{v}) \mathrm{NaCl}$ solution containing $75 \mu \mathrm{g}$ potassium penicillin $\mathrm{G} \mathrm{ml}^{-1}$ and $50 \mu \mathrm{g}$ streptomycin sulphate $\mathrm{ml}^{-1}$ at $37^{\circ} \mathrm{C}$. Oocytes were aspirated from antral follicles $(2-5 \mathrm{~mm}$ in diameter) with an 18 -gauge needle fixed to a $10 \mathrm{ml}$ disposable syringe and washed four times with maturation medium. Each group of ten cumulus-enclosed oocytes was then transferred to $100 \mu$ maturation medium, which had been covered previously with warm paraffin oil in a polystyrene culture dish $(35 \mathrm{~mm} \times 10 \mathrm{~mm}$; Becton Dickinson Labware, Lincoln Park, NJ) and equilibrated in an atmosphere of $5 \% \mathrm{CO}_{2}$ in air for about $3 \mathrm{~h}$, and was cultured at $38.5^{\circ} \mathrm{C}$ under the same atmospheric conditions. In a preliminary experiment, most oocytes cultured for $\mathrm{Oh}, 26 \mathrm{~h}$ and $46 \mathrm{~h}$ displayed the stages of germinal vesicle (GV), metaphase I (M-I) and metaphase II (M-II). Therefore, after culture for $0 \mathrm{~h}, 26 \mathrm{~h}$ and $46 \mathrm{~h}$, the cumuli of oocytes were completely (for observation of nuclear stage and CG distribution) or partially (for insemination) removed in the maturation medium containing $0.1 \%(\mathrm{w} / \mathrm{v})$ hyaluronidase from bovine testis (Sigma). The oocytes for insemination were washed twice in insemination medium incorporating $10 \mathrm{mmol}$ caffeine-sodium benzoate $1^{-1}$ (Sigma), and 5-7 oocytes were placed into $50 \mu \mathrm{l}$ the same medium and kept in a $\mathrm{CO}_{2}$ incubator $\left(5 \% \mathrm{CO}_{2}\right.$ in air at $\left.38.5^{\circ} \mathrm{C}\right)$ for $30 \mathrm{~min}$ until spermatozoa were added for IVF.

\section{Sperm preparation and in vitro fertilization}

Sperm-rich fractions of ejaculates were collected from Large White boars using the gloved-hand method. After adding $150 \mu \mathrm{g}$ potassium penicillin $\mathrm{ml}^{-1}$ and $100 \mu \mathrm{g}$ streptomycin sulphate $\mathrm{ml}^{-1}$, the semen was kept in an incubator at $16^{\circ} \mathrm{C}$ until needed. This procedure maintained the spermatozoa for I week without decreasing their penetration rates (W. H. Wang, M. Hosoe and Y. Shioya, unpublished). Before the spermatozoa were prepared for IVF, $0.5 \mathrm{ml}$ semen was added to 8-9 $\mathrm{ml} \mathrm{TCM}-199 \mathrm{~B}$ that had been previously equilibrated in an atmosphere of $5 \% \mathrm{CO}_{2}$ in air for about $3 \mathrm{~h}$. After mixing, the spermatozoa were washed three times in the same medium by centrifugation at $550 \mathrm{~g}$ for $5 \mathrm{~min}$. The sperm pellet was then resuspended to give a concentration of $2 \times 10^{\circ}$ cells $\mathrm{ml}^{-1}$. A $50 \mu \mathrm{l}$ sample was introduced into $50 \mu \mathrm{l}$ insemination medium incorporating $10 \mathrm{mmol}$ caffeine $\mathrm{I}^{-1}$ that contained the oocytes and was then cultured at $38.5^{\circ} \mathrm{C}$ in an atmosphere of $5 \% \mathrm{CO}_{2}$ in air. The mixture gave final concentrations of $5 \mathrm{mmol}$ caffeine $\mathrm{I}^{-1}$ and $1 \times 10^{6}$ spermatozoa $\mathrm{ml}^{-1}$. Before insemination (but after maturation culture) and 6-24 h after insemination, nuclear maturation, sperm penetration and CG distribution of the oocytes were evaluated.

\section{Labelling of oocytes}

The method used for labelling the CGs of oocytes was based on the report by Yoshida et al. (1993). Briefly, oocytes with or without the zona pellucida were fixed in PBS containing 3.7\% (w/v) paraformaldehyde (Sigma) for $30 \mathrm{~min}$ at room temperature and washed three times in PBS with $0.3 \%(\mathrm{w} / \mathrm{v}) \mathrm{BSA}$ (Fraction V; Seikagaku Kogyo Co. Ltd, Tokyo) and $100 \mathrm{mmol}$ glycine $\mathrm{I}^{-1}$ (Wako Pure Chemical Industries Ltd, Osaka). The zona pellucida was removed in PBS containing $0.1 \%(\mathrm{w} / \mathrm{v})$ pronase (Sigma). The oocytes were then treated for $5 \mathrm{~min}$ with $0.1 \%(\mathrm{v} / \mathrm{v})$ Triton X-100 (Sigma) in PBS. After washing twice, 

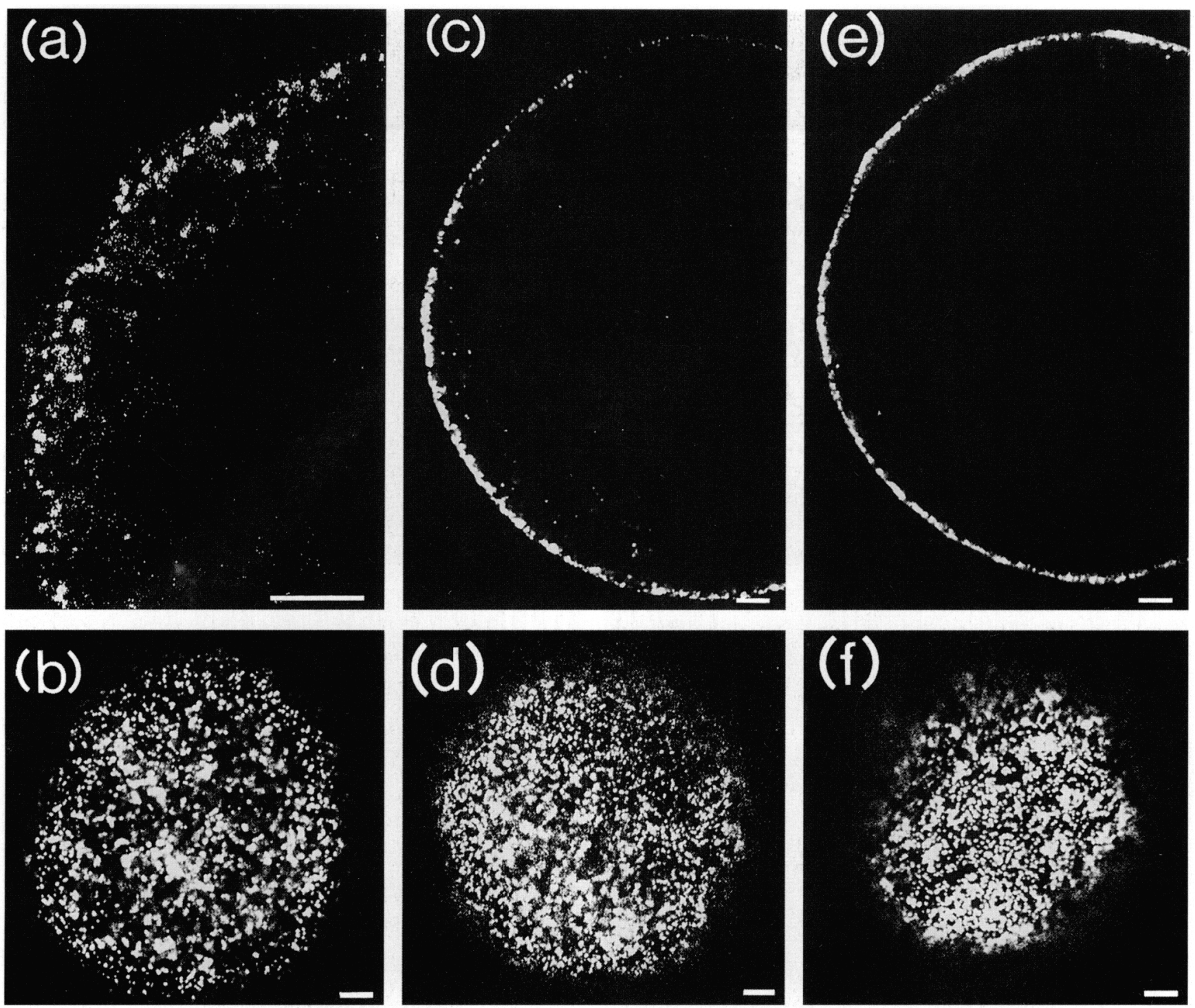

Fig. 1. Confocal microscope images of pig oocytes cultured for (a, b) 0 , (c, d) $26 \mathrm{~h}$ and (c, f) 46 h. (a) An oocyte with cortical granules (CGs) distributed in the cortex cytoplasm. ( $c$, e) A formed monolayer in the cortices (note that there are still a few CGs in the cortex cytoplasm in (c)). These images were taken at the equatorial section of oocytes stained with peanut agglutinin labelled with fluorescein isothiocyanate at (a) the germinal vesicle stage, (c) metaphase I and (e) metaphase II. (b, d, f) These are the same oocytes as those shown in (a), (c) and (e) but the images show their cortices (top surface) with a uniform CG distribution. Scale bars represent $8 \mu \mathrm{m}$.

oocytes were incubated in $100 \mu \mathrm{g}$ peanut agglutinin labelled with fluorescein isothiocyanate $\mathrm{ml}^{-1}$ (FITC-PNA; Sigma) in PBS for $30 \mathrm{~min}$. Nuclear status was evaluated by staining oocytes with $10 \mu \mathrm{g}$ bis-benzimide $\mathrm{H} 33342 \mathrm{ml}^{-1}$ (Calbiochem Co., La Jolla, CA) for 3-5 min. After being mounted under a coverslip on slides, the oocytes were observed under a fluorescent microscope and a laser confocal microscope.

\section{Nuclear evaluation and assessment of cortical gramules}

Stained oocytes were assessed on the same experimental day. The oocytes were first scored for their nuclear stages and sperm penetration under ultraviolet illumination using a epifluorescent microscope (Carl Zeiss). The assessment of maturation stages of oocytes was based on that reported by Wang et al. (1994). If oocytes had two pronuclei or one pronucleus with one or more penetrated sperm heads, they were considered to be nuclear-activated. After recording the nuclear stages, oocytes were observed under blue-violet illumination or laser confocal microscope (LSM410, Carl Zeiss) with an argon laser (wavelength of $488 \mathrm{~nm}$ ) and the distribution of CGs was classified according to their density. When the oocytes were labelled with FITC-PNA and observed under the fluorescent microscope and laser confocal microscope, fluorescent spots of different sizes could be observed within the cytoplasm; these fluorescent spots have been confirmed as CGs (Yoshida et al, 1993).

Cortical granules in cultured oocytes were examined for the formation of a monolayer just beneath the oolemma (Fig. 1). Cortical granule exocytosis of oocytes induced by sperm 

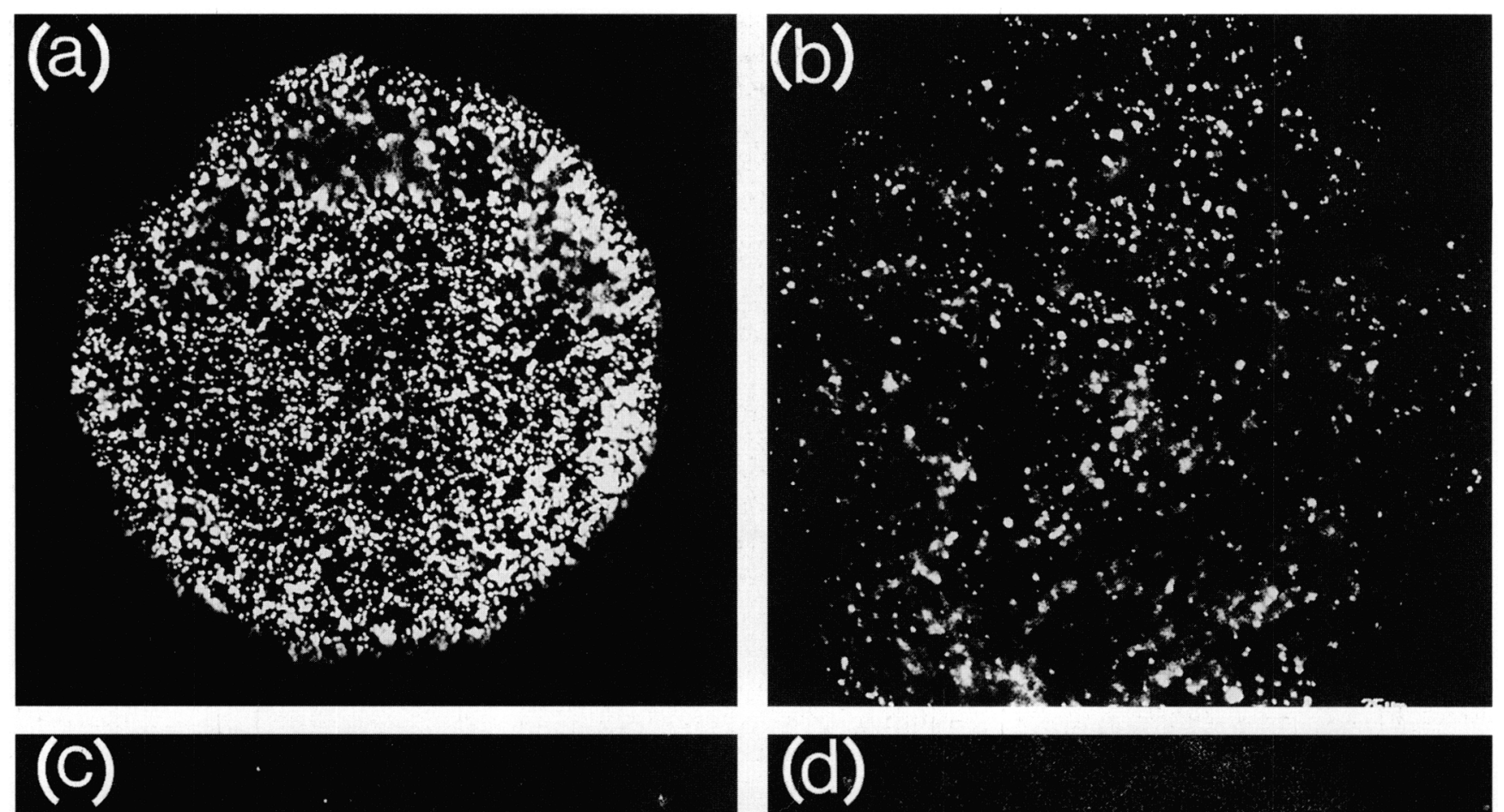

Fig. 2. Confocal microscope images of pig oocytes penetrated by spermatozoa, examined $18 \mathrm{~h}$ after insemination and stained with peanut agglutinin labelled with fluorescein isothiocyanatc. (a) Uniform and dense cortical granule (CG) distribution in the cortex; no CG exocytosis was found. (b, c) Partial and (d) complete CG release. Scale bar represents $8 \mu \mathrm{m}$.

penetration was evaluated according to the $C G$ densities in the oocyte cortex (the top surface of oocytes just beneath the oolemma). Three types of CG distribution were identified: (1) no CG exocytosis, in which CGs were distributed evenly in the cortex of the oocytes and there was no obvious difference in their density compared with control oocytes (the number of CGs ranged from 33 to 67 per $100 \mu^{2}$ ) (Fig. 2a); (2) partial CG exocytosis, in which most of the CGs had been lost, showing obvious decreased CG densities in the cortex compared with control oocytes (the number of CGs ranged from 1 to 15 per $100 \mu^{2}$ ) (Fig. 2b, c); and (3) complete CG exocytosis, in which the number of CGs was fewer than 1 per $100 \mu \mathrm{m}^{2}$ or no CG was observed in the oocytes (Fig. 2d). Control oocytes were the oocytes that were not inseminated or not penetrated by spermatozoa.

\section{Experinentul studies}

Two experiments were conducted in this study. In Expt I, CG distribution and CG exocytosis were examined before and $18 \mathrm{~h}$ after the IVF of oocytes cultured for $\mathrm{Oh}, 26 \mathrm{~h}$ and 46 h. In Expt 2, the time-dependent CG exocytosis was compared in oocytes cultured for $26 \mathrm{~h}$ and $46 \mathrm{~h}$. The oocytes were examined $6 \mathrm{~h}, 8 \mathrm{~h}, 18 \mathrm{~h}$ and $24 \mathrm{~h}$ after IVF. 
Table 1. Nuclear maturation and cortical granule distribution of pig oocytes during culture ${ }^{a}$

\begin{tabular}{|c|c|c|c|c|c|c|}
\hline \multirow[b]{2}{*}{$\begin{array}{l}\text { Time in } \\
\text { culture }\end{array}$} & \multirow{2}{*}{$\begin{array}{l}\text { Number of } \\
\text { oocytes } \\
\text { examined }\end{array}$} & \multicolumn{4}{|c|}{ Number of oocytes } & \multirow{2}{*}{$\begin{array}{l}\text { Number of } \\
\text { oocytes forming } \\
\text { a CG monolayer } \\
(\%)\end{array}$} \\
\hline & & $\begin{array}{l}\text { GV } \\
(\%)\end{array}$ & $\begin{array}{c}\text { GVBD } \\
(\%)\end{array}$ & $\begin{array}{l}\text { M-I } \\
(\%)\end{array}$ & $\begin{array}{c}\text { M-II } \\
(\%)\end{array}$ & \\
\hline 0 & 70 & $70(100)^{b}$ & $0(0)$ & $0(0)^{b}$ & $0(0)^{b}$ & $0(0)^{\mathrm{b}}$ \\
\hline 26 & 60 & $12(20)^{c}$ & $2(3)$ & $45(75)^{c}$ & $1(2)^{\mathrm{b}}$ & $46(77)^{c}$ \\
\hline 46 & 71 & $4 \quad(6)^{c}$ & $0(0)$ & $3(4)^{b}$ & $64(90)^{c}$ & $67(94)^{\mathrm{d}}$ \\
\hline
\end{tabular}

'Oocytes were cultured in TCM 199B supplemented with 10 iu pregnant mares' serum gonadotrophin $\mathrm{ml}^{-1}$ and 10 iu hCG $\mathrm{ml}^{-1}$ before examination; experiments were repeated three times.

b.c.dValues with different superscripts in the same column are significantly different $(P<0.001)$.

CG, cortical granule; GV, germinal vesicle; GVBD, GV breakdown; M-I, metaphase I; M-II, metaphase II.

Table 2. Cortical granule exocytosis in pig oocytes during maturation after penetration by spermatozoa ${ }^{a}$

\begin{tabular}{|c|c|c|c|c|c|c|}
\hline \multirow{2}{*}{$\begin{array}{l}\text { Time of } \\
\text { insemination } \\
\text { (h of culture) }\end{array}$} & \multirow{2}{*}{$\begin{array}{l}\text { Number of } \\
\text { oocytes } \\
\text { examined }\end{array}$} & \multirow{2}{*}{$\begin{array}{c}\text { Number of } \\
\text { oocytes } \\
\text { penetrated } \\
(\%)^{b}\end{array}$} & \multirow{2}{*}{$\begin{array}{c}\text { Number of } \\
\text { polyspermic } \\
\text { oocytes } \\
(\%)^{c}\end{array}$} & \multicolumn{3}{|c|}{$\begin{array}{c}\text { Number of oocytes with different } \\
\text { degrees of CG exocytosis }\end{array}$} \\
\hline & & & & $\begin{array}{l}\text { None } \\
(\%)^{c}\end{array}$ & $\begin{array}{c}\text { Partial } \\
(\%)^{c}\end{array}$ & $\begin{array}{l}\text { Complete } \\
(\%)^{c}\end{array}$ \\
\hline 0 & 33 & $28(85)$ & $24(86)$ & $28(100)^{\mathrm{d}}$ & $0 \quad(0)^{d}$ & $0 \quad(0)^{d}$ \\
\hline 26 & 48 & $47(98)$ & $38(81)$ & $9(19)^{\mathrm{e}}$ & $26(55)^{\mathrm{e}}$ & $12(26)^{e}$ \\
\hline 46 & 46 & $45(98)$ & $35(78)$ & $0 \quad(0)^{\mathrm{f}}$ & $7(16)^{\mathrm{f}}$ & $38(84)^{f}$ \\
\hline
\end{tabular}

${ }^{\mathrm{a}}$ Oocytes were examined $18 \mathrm{~h}$ after insemination and stained after removing the zona pellucida; experiments were repeated three times.

bercentage of the number of oocytes examined.

'Percentage of the number of oocytes penetrated by spermatozoa.

${ }_{\mathrm{d} e, e, V}$ alues with different superscripts within the same column are significantly different $(P<0.001)$.

CG, cortical granule.

\section{Statistical analysis}

Three replicate trials were carried out in each experiment; for each replicate, the percentage values for oocyte maturation, penetration, polyspermy and oocytes with different CG distributions and densities were subjected to an arc-sine transformation, and the transformed values were assigned for one-way (Expt 1) and two-way (Expt 2) ANOVA. When ANOVA revealed a significant treatment effect, the treatments were compared by Duncan's multiple range test.

\section{Results}

\section{Experiment 1}

All of the oocytes cultured for $\mathrm{Oh}$ (that is, just after collection) were at the GV stage of maturation (Table I). After $26 \mathrm{~h}$ of culture, $78 \%$ of oocytes had reached GVBD and M-I and only one had reached M-II. As the culture time increased to $46 \mathrm{~h}$, a significantly $(P<0.001)$ higher proportion of oocytes reached M-II $(90 \%)$. Cortical granules existed in the cortex cytoplasm of oocytes at the GV stage (Fig. 1a); as maturation progressed, CGs migrated centrifugally. This migration began after GVBD and by the time the oocytes had reached M-I or M-II almost all the CGs had migrated to cortex just beneath the oolemma and had formed a monolayer (Fig. Ic, e) except at the site where the first polar body was not completely extruded. All the oocytes showed uniform CG distribution in the cortex of oocytes at all stages (Fig. Ib, d, f). However, if the oocytes did not undergo GVBD, the CGs did not migrate even when they were cultured for $46 \mathrm{~h}$.

When examined $18 \mathrm{~h}$ after insemination, $85 \%, 98 \%$ and $98 \%$ of the oocytes cultured for $0 \mathrm{~h}, 26 \mathrm{~h}$ and $46 \mathrm{~h}$, respectively, were penetrated by spermatozoa and $86 \%, 81 \%$ and $78 \%$ of the oocytes, respectively, were polyspermic (Table 2). No significant difference was observed in the number of oocytes penetrated and the number of polyspermic oocytes among different culture times. None of the penetrated oocytes inseminated at $0 \mathrm{~h}$ of culture released CGs (Table 2). However, $81 \%$ and $100 \%$ of sperm-penetrated oocytes inseminated at $26 \mathrm{~h}$ and $46 \mathrm{~h}$ of culture released CGs, respectively (Figs 2, 3). A significantly higher $(P<0.001)$ proportion of oocytes cultured for $46 \mathrm{~h}$ completely released CGs compared with oocytes cultured for $26 \mathrm{~h}$ ( $84 \%$ versus $26 \%$ ).

Neither nuclear activation nor CG exocytosis were observed when oocytes were inseminated at the GV stage (cultured for 0 h) (Table 3). However, $38 \%$ and $96 \%$ of the oocytes cultured for $26 \mathrm{~h}$ and $46 \mathrm{~h}$ before insemination, respectively, had been activated forming a pronucleus, with significantly $(P<0.001)$ higher activation rates in the oocytes cultured for $46 \mathrm{~h}$. When complete CG exocytosis was analysed in nuclear-activated oocytes, no statistical difference $(P>0.05)$ was observed 


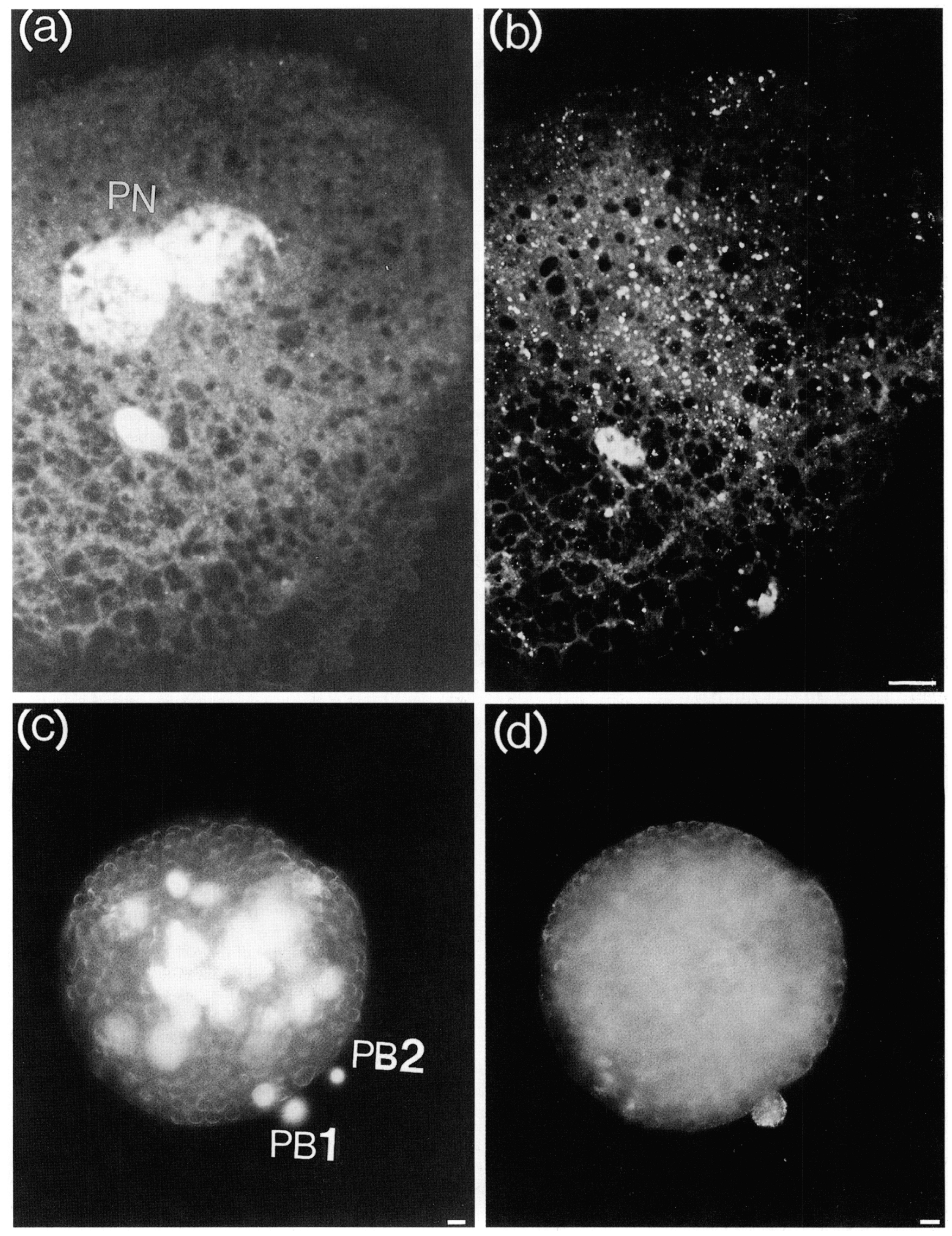


Table 3. Relationship between nuclear activation and cortical granule exocytosis in pig oocytes penetrated by spermatozoa during maturation

\begin{tabular}{|c|c|c|c|c|c|c|c|}
\hline \multirow{2}{*}{$\begin{array}{l}\text { Time } \\
\text { in culture } \\
\text { (h) }\end{array}$} & \multirow{2}{*}{$\begin{array}{c}\text { Number of } \\
\text { oocytes } \\
\text { penetrated }\end{array}$} & \multirow{2}{*}{$\begin{array}{l}\text { Number of } \\
\text { activated } \\
\text { oocytes } \\
(\%)^{b}\end{array}$} & \multirow{2}{*}{$\begin{array}{l}\text { Number of } \\
\text { monospermic } \\
\text { oocytes } \\
(\%)^{c}\end{array}$} & \multirow{2}{*}{$\begin{array}{l}\text { Number of } \\
\text { polyspermic } \\
\text { oocytes } \\
(\%)^{c}\end{array}$} & \multicolumn{3}{|c|}{$\begin{array}{l}\text { Number of oocytes releasing } \\
\text { CGs completely in oocytes }\end{array}$} \\
\hline & & & & & $\begin{array}{l}\text { Total } \\
(\%)^{c}\end{array}$ & $\begin{array}{c}\text { Monospermy } \\
(\%)^{d}\end{array}$ & $\begin{array}{c}\text { Polyspermy } \\
(\%)^{e}\end{array}$ \\
\hline 0 & 28 & $0 \quad(0)^{f}$ & - & - & - & $\ldots$ & - \\
\hline 26 & 47 & $18(38)^{g}$ & $3(17)$ & $15(83)$ & $12(67)$ & $2(67)$ & $10(67)$ \\
\hline 46 & 45 & $43(96)^{\mathrm{h}}$ & $10(23)$ & $33(77)$ & $33(77)$ & $8(80)$ & $30(91)$ \\
\hline
\end{tabular}

2Oocytes penetrated by spermatozoa as listed in Table 2 were evaluated.

bercentage of the number of oocytes penetrated by spermatozoa.

cPercentage of the number of activated oocytes.

dPercentage of the number of monospermic oocytes.

'Percentage of the number of polyspermic oocytes.

$f, g, h$ Values with different superscripts are significantly different $(P<0.001)$

CG, cortical granule.

Table 4. Time-dependent sperm penetration and cortical granule exocytosis in pig oocytes induced by sperm penetration during maturation $^{\mathrm{a}}$

Time of examination (h after insemination)
Time of insemination (h of culture)

$\begin{array}{cc}\text { Number of } & \begin{array}{c}\text { Number of } \\ \text { oocytes } \\ \text { oocytes }\end{array} \\ \text { examined } & (\%)^{\mathrm{b}}\end{array}$

examined

Number of oocytes with different degrees of CG exocytosis

\begin{tabular}{ccc}
\hline $\begin{array}{c}\text { None } \\
(\%)^{c}\end{array}$ & $\begin{array}{c}\text { Partial } \\
(\%)^{c}\end{array}$ & $\begin{array}{c}\text { Complete } \\
(\%)^{c}\end{array}$ \\
\hline
\end{tabular}

\begin{tabular}{|c|c|c|c|c|c|c|}
\hline \multirow[t]{2}{*}{6} & 26 & 26 & $15(58)^{d}$ & $13(87)^{d}$ & $2(13)^{d}$ & $0 \quad(0)^{d}$ \\
\hline & 46 & 35 & $24 \quad(69)^{d}$ & $14(58)^{e}$ & $8(33)^{e}$ & $2(8)^{d}$ \\
\hline \multirow[t]{2}{*}{8} & 26 & 32 & $30(94)^{\mathrm{ef}}$ & $14(47)^{\mathrm{e}}$ & $12(40)^{\mathrm{e}}$ & $4(13)^{d}$ \\
\hline & 46 & 25 & $21(84)^{\mathrm{e}}$ & $5(24)^{f}$ & $16(76)^{f}$ & $0 \quad(0)^{d}$ \\
\hline & 46 & 30 & $30(100)^{f}$ & $0 \quad(0)^{g}$ & $6(20)^{d}$ & $24(80)^{f}$ \\
\hline \multirow[t]{2}{*}{24} & 26 & 25 & $24(96)^{\mathrm{ef}}$ & $2(8)^{f g}$ & $12(50)^{\mathrm{e}}$ & $10(42)^{e}$ \\
\hline & 46 & 22 & $21 \quad(96)^{\text {ef }}$ & $0 \quad(0)^{g}$ & $4(19)^{d}$ & $17(8 I)^{f}$ \\
\hline
\end{tabular}

${ }^{a}$ Experiments were repeated three times.

bercentage of the number of oocytes examined.

${ }^{c}$ Percentage of oocytes penetrated by spermatozoa.

d.e.f,gValues with different superscripts within the same column are significantly different $(P<0.05)$.

CG, cortical granule.

between oocytes cultured for $26 \mathrm{~h}(67 \%)$ and $46 \mathrm{~h}(88 \%)$, or between monospermic $(67-80 \%)$ and polyspermic $(67-91 \%)$ oocytes.

\section{Experiment 2}

Six hours after insemination, $58 \%$ (oocytes cultured for $26 \mathrm{~h}$ ) and $69 \%$ (oocytes cultured for $46 \mathrm{~h}$ ) of the oocytes had been penetrated by spermatozoa (Table 4). However, a significantly
$(P<0.05)$ higher proportion of oocytes showed partial CG exocytosis in oocytes cultured for $46 \mathrm{~h}(33 \%)$ than in oocytes cultured for $26 \mathrm{~h}(13 \%)$. Oocytes cultured for $26 \mathrm{~h}$ were still at the M-I stage of maturation while oocytes cultured for $46 \mathrm{~h}$ were at the M-II stage. Complete CG exocytosis was observed in two $(8 \%)$ of the oocytes cultured for $46 \mathrm{~h}$ and these two oocytes were at the telophase II stage. The penetration of oocytes was almost finished $8 \mathrm{~h}$ after insemination, and by this time the penetration rate was significantly $(P<0.05)$ higher

Fig. 3. Fluorescent microscope images of oocytes cultured for $46 \mathrm{~h}$ and examined (a, b) $8 \mathrm{~h}$ and (c, d) $18 \mathrm{~h}$ after insemination. (a) Two pronuclei (PN) and one sperm head stained by H 33342 are indicated in this oocyte. (b) Partial release of cortical granule (CGs) from the oocyte in (a), stained with peanut agglutinin labelled with fluorescein isothiocyanate. (c) An oocyte penetrated by a large number of spermatozoa; the first (PBI)

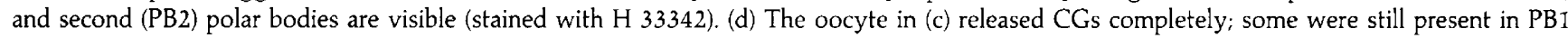
but not in PB2. Scale bars represent $8 \mu \mathrm{m}$. 
than at $6 \mathrm{~h}$; most of the oocytes also showed partial CG exocytosis with a significantly $(P<0.05)$ higher rate of exocytosis in oocytes cuitured for $46 \mathrm{~h}$. Four oocytes that had been cultured for $26 \mathrm{~h}$ were in telophase II and displayed complete $\mathrm{CG}$ exocytosis but other oocytes cultured for this time were still at the M-I stage; oocytes cultured for $46 \mathrm{~h}$ were at the M-II stage. The proportion of oocytes showing partial CG exocytosis decreased $18 \mathrm{~h}$ after insemination, while the proportion of oocytes showing complete CG exocytosis increased significantly $(P<0.05)$ in oocytes cultured for $26 \mathrm{~h}$ or $46 \mathrm{~h}$, compared with those examined $8 \mathrm{~h}$ after insemination. Complete CG exocytosis was observed in nuclear-activated oocytes. No further increase in nuclear activation or CG exocytosis was observed after prolonging the culture time after insemination to $24 \mathrm{~h}$. However, a significantly $(P<0.05)$ higher proportion of oocytes cultured for $46 \mathrm{~h}(80 \%$ and $81 \%)$ completely released their CGs $18 \mathrm{~h}$ and $24 \mathrm{~h}$ after insemination

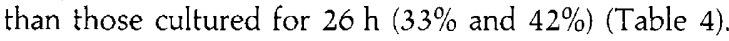

\section{Discussion}

This study provides evidence that sperm penetration cannot induce $C G$ exocytosis in immature pig oocytes with an intact GV. Cortical granule exocytosis took place in some oocytes after GVBD and in most of the oocytes at M-II, indicating that the competence of the cortical reaction in pig oocytes upon sperm penetration did not fully develop until M-II. However, delayed CG exocytosis was observed in both maturing and matured oocytes under the present experimental conditions.

The reason for the failure of immature oocytes to release CGs is unknown. The same results have been observed in sea urchins (Longo, 1978), hamsters (Moore and Bedford, 1978), rabbits (Barrios and Bedford, 1979), amphibians (Elinson, 1986), mice (Ducibella et al., 1988), starfish (Chiba et al., 1990) and cattle (W. H. Wang, M. Hosoe and Y. Shioya, unpublished). According to the study in mouse oocytes, this incompetence may be due to the absence of the cortical membrane system that stores and releases intracellular $\mathrm{Ca}^{2+}$ (Ducibella et al., 1988) because CG exocytosis is the result of intracellular $\mathrm{Ca}^{2+}$ release (Miyazaki, 1990). Mehlmann and Kline (1994) reported that fertilization of immature mouse oocytes was able to produce repetitive $\mathrm{Ca}^{2+}$ transients but the transients were much lower than in matured oocytes. These results were similar to those reported in starfish (Chiba et al., 1990) and hamsters (Fujiwara et al., 1993). Treatment with the calcium ionophore A23187 (Ducibella et al., 1990a, 1990b) and microinjection of inositol 1,4,5-trisphosphate (Ducibella et al., 1993) could not induce CG exocytosis in GV-intact mouse oocytes. We also found that A23187 could induce matured but not GV-intact pig oocytes to release CGs (W. H. Wang, M. Hosoe and Y. Shioya, unpublished). Taking these results together, it seems that an increase in $\mathrm{Ca}^{2+}$ concentration induced by A23187, inositol $1,4,5$-trisphosphate or spermatozoa is insufficient to activate the immature oocytes to release CGs.

The ability of oocytes to undergo a cortical reaction in response to penetration developed after stage M-I in mice (Ducibella and Buetow, 1994). In the study reported here, when oocytes that had undergone GVBD and had reached stage M-I were inseminated, most of the oocytes were able to release CGs, indicating that pig oocytes at these stages could be activated by sperm penetration. These results were consistent with previous reports that pig oocytes at the M-I stage could form pronuclei by sperm penetration (Nagai et al., 1991; Kikuchi and Nagai, 1993; Wang et al., 1994) and by electrical stimulation (Kikuchi et al., 1995). However, the proportion of oocytes with nuclear activation (Wang et al., 1994; Kikuchi et al., 1995; present results) and CG exocytosis (present results) in M-I were lower than those in M-II, indicating that the cytoplasmic maturation was not fully developed in most of the oocytes at M-I. However, we found that most of the oocytes $(67-88 \%)$ that had been activated to form a female pronucleus or both male and female pronuclei released all their CGs, suggesting that in these oocytes cytoplasmic maturation had developed.

Sathananthan and Trounson (1982) reported the delayed release of CGs in human oocytes fertilized in vitro, especially in polyspermic oocytes. In the present study, delayed CG exocytosis was observed in most of the oocytes, even in matured oocytes. However, delayed CG exocytosis was absent during normal in vivo fertilization (Cran and Cheng, 1986). It is possible the fertilization conditions resulted in this abnormal cortical reaction during IVF. The present IVF system is very effective for capacitation of boar spermatozoa (Niwa, 1993) but may not be suitable for oocytes to react upon sperm penetration. According to Cran and Cheng (1986), when pig oocytes are treated with A23187 in the same medium that was used for IVF, the CG exocytosis is largely affected by the presence of fetal calf serum and the amount of $\mathrm{Ca}^{2+}$ in the medium. Bovine oocytes matured and inseminated in vitro do not show high polyspermy but if the oocytes are inseminated in the medium with $10 \%$ fetal calf serum, the polyspermic penetration increases significantly from less than $30 \%$ without fetal calf serum to more than $80 \%$ with $10 \%$ fetal calf serum (Tajik et al., 1993). Although the cortical reaction was not examined, it is possible that fetal calf serum affected the reaction of oocytes, including CG exocytosis upon sperm penetration. Another possibility is the insufficient cytoplasmic maturation of pig oocytes cultured under in vitro conditions. The delayed CG exocytosis may result in the incomplete formation of CG envelope in the perivitelline space, thus resulting in polyspermic penetration into oocytes (Dandekar and Talbot, 1992). Kim et al. (1996) reported that when pig oocytes matured in vitro were precultured in oviductal fluid for $1.5 \mathrm{~h}$ before insemination, a complete cortical reaction takes place. They suggested that some glycoproteins from the oviductal fluid may enter the perivitelline space, facilitate the synchronous CG exocytosis and promote the reaction of the zona pellucida to CG extrudes. However, the exact mechanism used by pig oocytes to block polyspermy is still unclear.

In conclusion, pig oocytes are able to release CGs in response to penetration by spermatozoa after GVBD; this ability develops fully after maturation. Cytoplasmic maturation is responsible for CG exocytosis. Polyspermy may be the result of the complete failure of CG exocytosis in immature oocytes and delayed CG exocytosis in matured oocytes. Further experiments are necessary to clarify whether the abnormal cortical reaction in pig oocytes results from insufficient cytoplasmic maturation of oocytes matured in vitro or from the IVF 
conditions used in the present study. The methods used for examining CGs in the present study are useful to achieve these purposes.

This work was supported by Grant-in-Aid for the National Institute Postdoctoral Fellowship from the Research Development Corporation of Japan (JRDC). W. H. Wang was a recipient of a National Institute Postdoctoral Fellowship from JRDC. The authors thank $Q$. Sun for helping to prepare the manuscript.

\section{References}

Barrios M and Bedford JM (1979) Oocytes maturation: aberrant post-fusion responses of the rabbit primary oocytes to penetrating spermatozoa Journal of Cell Science 39 1-12

Barros C and Munoz G (1974) Sperm penetration through the zona pellucida of immature hamster oocytes Acta Physiology Latinoamerica 24 612-615

Chiba K, Kado RT and Jaffe LA (1990) Development of calcium release mechanisms during starfish oocyte maturation Developmental Biology $\mathbf{1 4 0}$ 300-306

Cran DG and Cheng WTK (1986) The cortical reaction in pig oocytes during in vivo and in vitro fertilization Gamete Research 13 241-251

Dandekar P and Talbot P (1992) Perivitelline space of mammalian oocytes: extracellular matrix of unfertilized oocytes and formation of a cortical granule envelope following fertilization Molecular Reproduction and Development 31 135-143

Ducibella T (1991) Mammalian egg cortical granules and the cortical reaction. In Elements of Mammalian Fertilization pp 205-230 Ed. PM Wasserman. CRC press, Bacca Raton

Ducibella T and Buetow J (1994) Competence to undergo normal, fertilizationinduced cortical activation develops after metaphase I of meiosis in mouse oocytes Developmental Biology 165 95-104

Ducibella T, Rangarajan S and Anderson E (1988) The development of mouse oocyte cortical reaction competence is accompanied by major changes in cortical vesicle and not cortical granule depth Developmental Biology 130 789-792

Ducibella T, Duffy P, Reindollar R and Su B (1990a) Changes in the distribution of mouse oocyte cortical granules and the ability to undergo the cortical reaction during gonadotropin-stimulated meiotic maturation and aging in vivo. Biology of Reproduction $\mathbf{4 3} 870-876$

Ducibella T, Kurasawa S, Rangarajan S, Kopf GS and Schultz RM (1990b) Precocious loss of cortical granules during mouse oocyte meiotic maturation and correlation with an egg-induced modification of the zona pellucida Developmental Biology 137 46-55

Ducibella T, Kurasawa S, Duffy P, Kopf GS and Schultz RM (1993) Regulation of the polyspermy block in the mouse egg: maturation-dependent differences in cortical exocytosis and zona pellucida modifications induced by inositol 1,4,5-trisphosphate and an activator of protein kinase C Biology of Reproduction 48 1251-1257

Elinson RP (1986) Fertilization in amphibians: the ancestry of the block polyspermy International Review of Cytology 101 59-93

Fujiwara J. Nakada K, Shirakawa H and Miyazaki S (1993) Development of inositol trisphosphate-induced calcium release mechanism during maturation of hamster oocytes Development 156 64-79

Hunter RHF, Cook B and Baker TC (1976) Dissociation of response to injected gonadotrophin between the Graafian follicle and oocyte in pigs Nature $\mathbf{2 6 0}$ 156-157

Iwamatsu T and Chang MC (1972) Sperm penetration in vitro of mouse oocytes at various times after maturation Journal of Reproduction and Fertility 31 237-247

Kikuchi K and Nagai T (1993) Pig follicular oocytes penetrated at metaphase-I can form female and male pronuclei Theriogenology 39244 (Abstract)
Kikuchi K, Nagai T and Izaike Y (1995) Cytoplasmic maturation of pig follicular oocytes arrested at metaphase-I Theriogenology 43247 (Abstract)

Kim N-H, Funahashi H, Abeydeera LR, Moon SJ, Prather RS and Day BN (1996) Effects of oviductal fluid on sperm penetration and cortical granule exocytosis during fertilization of pig oocytes in vitro. Journal of Reproduction and Fertility 107 79-86

Longo FJ (1978) Insemination of immature sea urchin (Arbacia punctulata) eggs Developmental Biology 62 271-291

Marrs RP, Saito H, Yee B, Sato F and Brown J (1984) Effect of variation of in vitro culture techniques upon oocyte fertilization and embryo development in human in vitro fertilization procedures Fertility and Sterility 41 519-523

Mehlmann LM and Kline D (1994) Regulation of intracellular calcium in the mouse egg: calcium release in response to sperm or inositol trisphosphate is enhanced after meiotic maturation Biology of Reproduction 51 1088-1098

Miyazaki S (1990) Cell signalling at fertilization of hamster eggs Journal of Reproduction and Fertility Supplement 42 163-175

Moore HDM and Bedford JM (1978) Ultrastructure of the equatorial segment of hamster spermatozoa during penetration of oocytes Journal of Ultrastructure Research $62 \quad 110-117$

Nagai T, Kikuchi K and Motlik J (1991) In vitro fertilization of pig follicular oocytes at metaphase-I Theriogenology 35248 (Abstract)

Niwa K (1993) Effectiveness of in vitro maturation and in vitro fertilization techniques in pigs Journal of Reproduction and Fertility Supplement $\mathbf{4 8}$ 49-59

Niwa K and Chang MC (1975) Fertilization of rat eggs in vitro at various times before and after ovulation with special reference to fertilization of ovarian oocytes matured in vitro. Journal of Reproduction and Fertility 43 435-451

Niwa K, Park C-K and Okuda K (1991) Penetration in vitro of bovine oocytes during maturation by frozen-thawed spermatozoa Journal of Reproduction and Fertility 91 329-336

Overstreet JW and Bedford JM (1974) Comparison of the penetrability of the egg vestments in follicular oocytes, unfertilized and fertilized ova of the rabbit Developmental Biology 41 185-192

Overstreet JW, Yanagimachi R, Katz DF, Hayashi K and Hanson FW (1980) Penetration of human spermatozoa into the human zona pellucida and the zona-free hamster eggs: a study of fertile donors and infertile patients Fertility and Sterility 33 534-542

Polge C and Dzuik P (1965) Recovery of immature eggs penetrated by spermatozoa following induced ovulation in the pig Journal of Reproduction and Fertility 9 357-358

Sathananthan AH and Trounson AO (1982) Ultrastructure of cortical granule release and zona interaction in monospermic and polyspermic human ova fertilized in vitro. Gamete Research 6 225-234

Tajik P, Niwa K and Murase T (1993) Effects of different protein supplements in fertilization medium on in vitro penetration of cumulus-intact and cumulusfree bovine oocytes matured in culture Theriogenology 40 949-958

Trounson AO, Mohr LR, Wood C and Leeton JF (1982) Effect of delayed insemination on in vitro fertilization, culture and transfer of human embryos Journal of Reproduction and Fertility 64 285-294

Wang WH, Abeydeera LR, Okuda K and Niwa K (1994) Penetration of porcine oocytes during maturation in vitro by cryopreserved, ejaculated spermatozoa Biology of Reproduction 50 510-515

Wang WH, Abeydeera LR, Fraser LR and Niwa K (1995) Functional analysis using chlortetracycline fluorescence and in vitro fertilization of frozenthawed ejaculated boar spermatozoa incubated in a protein-free chemically defined medium Journal of Reproduction and Fertility 104 305-313

Yanagimachi R (1994) Mammalian fertilization. In The Physiology of Reproduction pp 268 Eds E Knobil and JD Neill. Raven Press, New York

Yoshida M, Cran DG and Pursel VG (1993) Confocal and fluorescence microscopic study using lectins of the distribution of cortical granules during the maturation and fertilization of pig oocytes Molecular Reproduction and Development 36 462-468 